\title{
O CASAMENTO, SOB A ÓTICA DA FIGURA FEMININA, NA CONTÍSTICA DE SONIA COUTINHO
}

\author{
Fernanda dos Santos Silva; Luiz Antonio de Carvalho Valverde; \\ 1. Bolsista PROBIC/UEFS, Graduanda em Licenciatura em Letras Vernáculas, Universidade Estadual de Feira de Santana, e- \\ mail: fernandafsafsa@hotmail.com \\ 2. Orientador, Departamento de Letras e Artes, Universidade Estadual de Feira de Santana, e-mail: lacvalverde@uol.com.br
}

PALAVRAS-CHAVE: Narrativas; Sonia Coutinho; Crítica Feminista.

\section{INTRODUÇÃO}

As narrativas acompanham a humanidade sejam elas orais ou escritas. Além de contar histórias, ocupam a função de transmissão de concepções de mundo, experiências individuais e coletivas. Narrar é, também, assumir um ponto de vista para enunciar a história. A história nos é transmitida a partir de perspectivas e, durante muito tempo, foi predominante e, muitas vezes, única, a perspectiva a partir da qual se falou sobre temas do universo feminino.

Reconhecendo a necessidade de analisar outras perspectivas, analisamos, neste trabalho, obras da escritora baiana Sonia Coutinho a fim de compreender como se estabelece o discurso sobre o casamento pelas personagens presentes nos contos.

A literatura de autoria feminina é, sobretudo, um caminho importante para problematizarmos as representações ou não representações da mulher no âmbito literário e, de acordo com Luiza Lobo (2000), é um caminho pelo qual perpassa o discurso de "alteridade":

$\mathrm{Na}$ literatura de autoria feminina, como na literatura de autoria negra ou africana, percebe-se a existência de um discurso de alteridade político, na medida em que seus representantes se assumam e se declarem como tal, isto é, [...] como parte de uma etnia não prestigiada ou como mulheres. A literatura de autoria feminina se constitui naquelas obras em que a literatura se exerce como tomada de consciência de seu papel social. (LOBO, 2000, p.3)

É pertinente que não desvinculemos da narrativa o discurso, pois como nos diz Gérard Gennete (1995), narrativa e discurso estão interligados: "História e narração só existem para nós, pois, por intermédio da narrativa. Enquanto narrativo, vive da sua relação com a história que conta; enquanto discurso, vive da sua relação com a narração que o profere" (GENNETE, 1995, p.47). Nesta pesquisa, tivemos como objetivo investigar o discurso das personagens e como este se articula com os debates sobre gênero e identidade. A escolha do tema casamento se dá pela necessidade de rediscutir o papel de esposa, atribuído, ao decorrer da história, às mulheres.

De acordo com Georges Duby (1989), no período medieval, as mulheres, primeiramente, dentro de um sistema de vigilância familiar controlada pela figura do pai, são direcionadas a outra família. Após essa etapa, passam a ser vistas como garantia da sucessão familiar através do casamento, dessa forma, o fato de ser mulher as condiciona a um destino detalhadamente planejado e com finalidades, primordialmente, financeiras.

Casar tornava-se sinônimo de proteção e estabilidade. Não só o papel de esposa as acompanha, mas também o de mãe e quando esses papéis não eram desempenhados satisfatoriamente, sobre elas recaiam as críticas.

Esta ideia persiste no imaginário e se faz presente inclusive na produção literária. As lutas do movimento feminista vêm para tentar desestabilizar as imagens negativas que foram 
construídas, histórica e socialmente, para as mulheres. A literatura de autoria feminina, segundo Luiza Lobo (2000), cumpre ainda mais o seu papel quando traz à tona outras vivências diferentes das convencionais para a mulher.

As análises feitas da contística de Sonia Coutinho nos permitem visualizar uma nova configuração de escrita e de perfil de mulher que se delineiam a partir das décadas de 60 e 70 . Entendemos que as narrativas comportam uma multiplicidade de vozes e de identidades e, de certa forma, são representativas do sujeito moderno.

\section{MATERIAL E MÉTODOS OU METODOLOGIA (ou equivalente)}

Utilizamos, para a realização do objetivo deste trabalho, a crítica literária feminista a partir das considerações de Lúcia Osana Zolin. Para complementar a pesquisa sobre identidade e gênero, recorremos a Stuart Hall e Judith Butler. No que diz respeito aos aspectos estéticos das narrativas, utilizamos teóricos como Júlio Cortázar, Nádia Battela Gotlib e Walter Benjamin. E, também, fizemos consultas a artigos, teses e monografias a fim de compreender melhor nosso objeto de estudo.

\section{RESULTADOS E/OU DISCUSSÃO (ou Análise e discussão dos resultados)}

A autora escolhida para este estudo, Sonia Coutinho, nasceu em 1939, na cidade Itabuna-Ba, e residiu, a maior parte de sua vida, na cidade do Rio de Janeiro. Há diversos estudos realizados no Brasil e no exterior a respeito de suas obras. Há uma recorrência, em sua contística, de personagens ambientadas, na cidade do Rio de Janeiro, e tentam se desvincular do modelo ideal de mulher, concomitante a isso enfrentam também o dilema do isolamento já que são mulheres que saem da sua terra natal e necessitam conciliar sua independência à falta de apoio dos familiares. A sua contística é marcada, segundo Lilian Santana da Silva (2010), por um novo perfil de mulher: "Suas personagens são mulheres sozinhas, lutando para ganhar a vida, fora do casamento e da teia patriarcal da família, mulheres de classe média baixa, profissionais. Um modelo de mulher que começa a se afirmar no Brasil, em torno dos anos 1970." (SILVA, 2010, p.48).

As produções literárias de mulheres que seguem aos anos 70 geram novas imagens para a mulher na literatura, essas novas representações precisam também de um diferente dispositivo teórico. A crítica literária feminista surge em resposta a essas novas produções. Segundo Lúcia Osana Zolin (2003), este modo de ler o texto literário é um dos resultados do movimento feminista:

[...] trata-se de um movimento político bastante amplo que, alicerçado na crença de que, consciente e coletivamente, as mulheres podem mudar a posição de inferioridade que ocupam no meio social, abarca desde reformas culturais, legais e econômicas [...] até uma teoria feminista acadêmica, voltada para reformas relacionadas ao modo de ler o texto literário. (ZOLIN, 2003, p.220)

Justifica-se este trabalho, uma vez que é na literatura o espaço para pensarmos diversas questões acerca do homem e das relações que ele mantém com a sociedade. É pensando na variedade de espaços que a mulher pode ocupar e da multiplicidade de identidades que pode abrigar o gênero feminino, uma vez que Judith Butler defende a necessidade de não procurar fixar uma identidade, pois existem mulheres e não uma identidade homogênea, propusemo-nos, neste trabalho, a analisar as diferentes vozes que 
emergem da narrativa da escritora Sonia Coutinho através de personagens que não se reconhecem nas construções as quais lhe foram impostas e desafiam a sociedade que as cerca a fim de se reafirmarem como mulheres que desejam buscar outro modus operandi diferente das mulheres que as precederam.

Analisando o livro Venenos de Lucrécia (1978), encontramos o conto "Cordélia, a caçadora”, em que a personagem questiona a condição em que se encontra:

Você não sabe o que fazer, Cordélia, e pensa que a vida é bem diferente do que uma pobre mulher poderia imaginar. Talvez deva aceitar tudo como natural. Mas, como irá encaixar essas Tarefas Secretas no quadro róseo de sua vida que costuma traçar para as colegas de repartição? (COUTINHO, 1978, p.25)

Para Rosana Ribeiro Patricio (2006), esta personagem é tanto caça quanto caçadora: “[...] a protagonista cultiva a imagem de mulher desprotegida, atraindo consequentemente um tipo de homem que busca mulheres dependentes e submissas sobre as quais possam exercer seu poder e afirmar sua masculinidade. Ela 'caçava' seu marido ideal e, ironicamente, também era uma caça." (PATRICIO, 2006 p.40). A narrativa descontrói o estereótipo à medida que a personagem recusa a submissão assumindo outra maneira de viver.

A personagem recusa a opressão, a partir do rompimento com a estrutura em que o personagem Papá a coloca como objeto, uma vez que ela passa a viver de acordo com seus desejos e não com os ditames do personagem masculino, como está exemplificado no trecho abaixo:

Nós partiremos quase correndo, logo depois que Papá sair para o escritório. Nada avisaremos à empregada e levaremos apenas a roupa do corpo e uma pequena valise, com objetos pessoais. Na bolsa, o endereço de uma pensão, indicada por uma colega de trabalho. (Agora, todas já saberão do fracasso do Mito Dourado, nosso casamento [...] (COUTINHO, p.27)

Ao utilizar o pronome nós, a narrativa passa do nível da personagem para incluir outras histórias. Dessa forma, a narrativa dá visibilidade a outras mulheres e a dialoga com a coletividade.

Encontramos, na contística de Sonia Coutinho, diversas marcas intertextuais, uma delas é a referência a atrizes, nomes do mundo da música e do cinema. Ao utilizar nomes conhecidos, a narradora trabalha com elementos ficcionais e não-ficcionais, a história das personagens se confunde com a história das mulheres que são citadas. E, dessa forma, a história se entrecruza com outras vozes de uma identidade do que é ser mulher que não pode funcionar a partir das lentes dos estereótipos.

\section{CONSIDERAÇÕES FINAIS (ou Conclusão)}

Os contos analisados possuem personagens que almejam por independência. Mulheres que colocadas por outros, na maioria das vezes, em um padrão de vida que não as satisfaz, desvinculam-se dos estereótipos a partir da desconstrução da imagem que família, amigos, filhos, marido construíram da figura "mulher". Se o previsível para a mulher, por muito tempo, foram os caminhos do casamento e da maternidade, as personagens das narrativas estudadas rompem com o cerceamento do corpo, do prazer, e lançam-se, imprevisivelmente, em uma trajetória de descobertas e, consequentemente, deparam-se com múltiplas possibilidades de ser mulher. 


\section{REFERÊNCIAS}

BUTLER, Judith. Problemas de Gênero: Feminismo e Subversão de Identidade. Tradução de Renato Aguiar. Rio de Janeiro: Editora Civilização Brasileira, 2003.

COUTINHO, Sonia. Os Venenos de Lucrécia. São Paulo: Ática, 1978

DUBY, Georges. Idade Média, idade dos homens: do amor e outros ensaios. Tradução de

Jônatas Batista Neto. São Paulo: Companhia das Letras, 1989.

GENETTE, G. Discurso da narrativa. Lisboa: Vega, 1995.

LOBO, Luiza. A literatura feminina na América Latina. Revista Brasil de Literatura. Disponível em: <http://members.tripod.com/ lfilipe/LLobo.html>. Acesso em: 05 ago. 2018.

PATRÍCIO, Rosana. As filhas de Pandora: Imagens da mulher na ficção de Sonia Coutinho: Rio de Janeiro, 7 letras, 2006.

SILVA, Lilian Santana da. O corpo na contística de Sonia Coutinho: uma leitura feminista. Dissertação (Mestrado)- Universidade Federal da Bahia, faculdade de Filosofia e Ciências Humanas, 2010. Disponível em: < https://repositorio.ufba.br/ri/handle/ri/11738> Acesso em: 18 mar. 2017.

ZOLIN, L.O., Crítica feminista. In: BONNICI, T.; ZOLIN,. L.O. (Org.). Teoria literária: abordagens históricas e tendências contemporâneas. Maringá: Eduem, 2003 . 